\title{
Supply Chain Inventory Model with Markov Chain Demand
}

\author{
Zhi-Ping Lin \\ Department of industrial engineering and management, National Taipei University and Technology \\ Su-Ping Ho \\ Department of industrial engineering and management, National Taipei University and Technology, \\ t104749001@ntut.edu.tw
}

Follow this and additional works at: https://jmstt.ntou.edu.tw/journal

Part of the Fresh Water Studies Commons, Marine Biology Commons, Ocean Engineering Commons, Oceanography Commons, and the Other Oceanography and Atmospheric Sciences and Meteorology Commons

\section{Recommended Citation}

Lin, Zhi-Ping and Ho, Su-Ping (2021) "Supply Chain Inventory Model with Markov Chain Demand," Journal of Marine Science and Technology. Vol. 29: Iss. 4, Article 5.

DOI: 10.51400/2709-6998.1585

Available at: https://jmstt.ntou.edu.tw/journal/vol29/iss4/5

This Research Article is brought to you for free and open access by Journal of Marine Science and Technology. It has been accepted for inclusion in Journal of Marine Science and Technology by an authorized editor of Journal of Marine Science and Technology. 


\title{
RESEARCH ARTICLE \\ Supply Chain Inventory Model with Markov Chain Demand
}

\author{
Zhi-Ping Lin, Su-Ping Ho* \\ Department of Industrial Engineering and Management, National Taipei University and Technology, Taiwan
}

\begin{abstract}
This study aims to develop a new one-vendor multiple-buyers integrated inventory model. We believe that our proposed model can forecast the demand of all buyers in the coming future by using data that have already existed and to minimize the total cost-for both buyers and vendors. In recent days, the Markov chain approach has played one of the critical methods of demand forecasting in the Supply Chain Management (SCM) field. The proposed model of this study is to analysis the demand of all buyers in one specific season that was impacted by the demand in the same season from last year. Finally, the results of this article discover the most optimal number of buyers and shipments, and the quantity of demand per period. Furthermore, a sensitivity analysis is also conducted to find out the sensitivity of the new model.
\end{abstract}

Keywords: Supply chain management (SCM), Markov chain, Demand forecasting

\section{Introduction}

S upply chain is composed of numerous entities such as manufacturers, vendors and retailers.

With the rapid development of the market, focusing on two-layer inventory problem is not enough. That is, multi-echelon inventory problem has now become one of the most significant issues in supply chain management (SCM). To remain competitive, decision makers must cooperate with all members in the supply chain. As a result, more and more researchers began to integrate the whole supply chain rather than just focusing on a single echelon, such as Taebok Kim [12]; who developed a generalized model of a serial multi-echelon supply chain and Yang and Kuo [25]; who developed a threeechelon inventory model to determine optimal joint total profits of the whole supply chain system based on Yang's [26] former study.

The integrated inventory model; one type of mathematical method, is a critical issue of decision makers in determining the quantity of inventories for both vendors and buyers to achieve the system's optimal profits. Only by collaborating all members in the supply chain, could the whole system improve its service level and reduce its total costs by Ben-Daya et al. [3]. By considering equal-sized shipments to the buyer, Lu [18] presented a heuristic approach for the one-vendor multi-buyer integrated inventory case in 1995 . He relaxed the assumption of Goyal [7] about completing a batch before starting shipments and investigated a model that allows shipments to occur during production. According to the spirit of Supply Chain Management, stable partnerships have to be established between all Vendors and buyers in systems to ensure the lowest total cost and the optimum profits by Lambert's [14] study. Recently, there are a lot of researchers have used the integrated model to deal with multi-echelon problems. By using a singlevendor multi-buyer integrated production-inventory model, J.K.Jha [11] found out that vendor's holding cost and set up cost show just opposite performance on shipment lot size. Christoph and Teabok [4] developed a multi-vendor single-buyer integrated inventory model to study shipment

Received 3 September 2020; revised 23 October 2020; accepted 28 January 2021.

Available online 3 September 2021.

* Corresponding author.

E-mail address: t104749001@ntut.edu.tw (S.-P. Ho). 
consolidation. Shah and Chaudhari [23] developed an integrated inventory model to study the improvement of deteriorating items. Poonam and Azharuddin [21] attempted to study the ordering strategies for an integrated inventory model with capacity constraint and order size dependent trade credit. In this paper, to satisfy the demand of buyers and minimize the total cost, one Vendor and several buyers in the system are supposed to reach an agreement on inventory planning through this partnership. That is, how high the profits would be, to a large extent, is depending on how much integrated inventory cost could be cut.

Traditional models can only help determine an optimal solution for one of the parties in the system. To address this situation, Banerjee developed the joint economic lot size (JELS) model [2]; which can help determine a joint optimal solution for all parties in the system. To break the barrier, Banerjee developed the JELS model, which can help find a jointly optimal policy for all parties in the system. To minimize the total costs of the whole supply chain system, many scholars today build their models based on the concept of JELS. Leuveano et al. [15] built a new JELS model to minimize joint total cost between vendor and buyer by deciding optimal delivery lot size, number of deliveries, and batch production. Abdelsalam and Elassal [1] considered the JELS problem for multi-echelon supply chain with multi-retailers and single manufacturer and supplier. Sarakhsi et al. [22] studied a single vendorsingle buyer supply chain of a single product by using a new JELS model.

The concept of Economic Order Quantity (EOQ) was firstly introduced by Ford W. Harris in 1913 [9]. EOQ is a kind of Fixed Order Quantity Model, which is applicable only when demand for a product is constant over the year and each new order is delivered in full when inventory reaches zero, and is always used to minimize ordering costs and inventory costs of systems by determining the exact quantity of goods per shipment. However, there are varieties of uncertain factors in practice cases. Thus, how to response to those uncertainties is one of the main challenges in supply chain management [17]. This paper will consider two of those uncertain factors, lead time and demand-to make the model more realistic.

Ouyang and $\mathrm{Wu}$ [20] maintained that shorter lead time could reduce the safety stock, improve the whole system's service level and help the company have much stronger competitive. Chandra and Grabis [6] indicated that short lead time could enhance the service level and lower inventory level effectively. Nevertheless, since lead time consists of order preparation, order transit, supplier lead time, delivery time and set-up time [24], it is really hard for researchers to estimate lead time and the demand during the lead time precisely. In order to make models much more realistic, more and more researchers begin to use normal distribution lead time or assume that the demand during led time is normally distributed. For instance, M.A.Hoque [10]; developed a vendor-buyer integrated production inventory model with normal distribution of lead time to find out the optimal solution of the model.

Numerous studies have assumed that the demand of buyers is constant over time. However, in practice, demands of buyers can easily be effected by other factors. That is, if researchers want to develop a realistic model, they have to consider fluctuating demand. Kocer [13] proposed a modified Markov Chain model to forecast intermittent demand. This paper will also adopt Markov Chain method to forecast the future demand. Markov Chain was first developed and introduced by the Russian mathematician Andrey Andreevich Markov [19]. His papers on Markov chains adopted the theory of determinants (of finite square matrices), and focused heavily on what are in effect finite stochastic matrices [5]. A rough description of the conception of Markov Chain is introduced in the follows.

Suppose that for any $n \mathrm{X} 1$ probability vector $X_{0}, X_{t}$ in the equation $X_{t}=A^{t} X_{0}$ (where $\mathrm{A}$ is a nxn transition matrix, all elements of which are all positive and the sum of each line is 1) would tend to a constant matrix $X$ as $t$ tends to positive infinite $(\mathrm{AX}=\mathrm{X})$. For example, supposed that there is a $3 \times 3$ probability vector $A$, all elements of which meet the following condition: $a+$ $b+c=d+e+f=g+h+i=1$, and a $3 \times 1$ probability vector $X_{t}$, where the sum of all elements $\left(x_{t}, y_{t} a n d z_{t}\right)$ equals to $1 . a, b$ and $c$ represent incidences of three different conditions of the event in the next period while the condition of this period is $x$. Similarly, $d, e$ and $f$ represent possibilities of three different conditions of the event while the condition of this period is $y . g, h$ and $i$ represent possibilities of three different conditions of the event while the condition of this period is $z . x_{k}, y_{k} a n d z_{k}$ present the incidences of three different conditions respectively in period $t$. Just like the process presented in appendix 1 , with $t$ approaches infinite, $X_{t}$ tends to a constant probability vector and the equation $X_{t}=A X_{t-1}$ becomes $X_{t}=A X_{t}$. This process is called as Markov Chain.

Nowadays, Markov Chain has already been widely applied to numerous fields that have 
something to do with probability, such as statistics, biology and economics. In this study, we used a Markov chain to determine the possibility of the constant increase in demand by $\rho$, no change in demand, and the decrease in demand by $\rho$ in a specific season.

Combining integrated the inventory model, concepts of SCM, JELS and EOQ, and the spirit of Markov chain, this paper would build a new model to find out the best strategy for decision makers to gain the optimal profit, and to determine the exact value of the total profit of the system.

\section{Model formulation}

Regarding the number of buyers, number of shipments of buyer $\mathrm{j}$ per period in season $\mathrm{k}$ and demand per period for all buyers in season $k$ these three elements as three decision variables of the system, this section is going to set up the onevendor multiple-buyers integrated inventory model with the spirit of Markov chain, deducing the general function of the profit of the whole system.

\subsection{The definition of the symbols}

The following are the definition of all 25 notations used in the proposed model:

$m$; Number of buyers

$j$; A subscript used to represent different buyers

$k$; A subscript used to represent different seasons in one year

$S$; Setup cost per lot $(\$ / \text { lot })_{4}$

$D$; Demand per year ( $\mathrm{D}=\sum_{k=1}^{4} D_{k}$, units/year)

$D_{k}$; Demand for all buyers in season $k\left(D_{k}=\right.$ $\left.\sum_{j=1}^{m} d_{j k}\right)$

$d_{j k}$; Demand for buyer $j$ in season $k$

$P$; Production per season (units/season)

$n_{j k}$; Number of shipments of buyer $\mathrm{j}$ per period in season $k$ (times/period)

$q_{j}$; Number of goods per shipment of buyer $j$ (units/shipment)

$Q_{k}$; Demand per period for all buyers in season

$$
k\left(Q_{k}=\sum_{j=1}^{m} n_{j k} q_{j}\right)
$$

$H_{v}$; Vendor's holding cost per unit per season (\$/unit/season)

$H_{b j}$; Buyer j's holding cost per unit per season (\$/unit/season)

$C_{o}$; Ordering cost per order (\$/order)

$C_{s} ;$ Subcontracting cost per unit (\$/unit)
$C_{d}$; Disposing cost per unit (\$/unit)

$C_{t}$; Transportation cost per shipment

(\$/shipment)

$P_{c}$; Production cost

$S_{p}$; Sale price

$L$; Leading time

$F_{j}$; The standard variance of buyer j's sales volume during the leading time

$\rho$; The percentage by which the demand in season $\mathrm{k}$ might increase or decrease

$\alpha_{k}$; Possibility of the actual demand in season $k$ increasing by $\rho$

$\beta_{k}$; Possibility of the actual demand in season $k$ is exactly same as the expected demand

$\gamma_{k}$; Possibility of the actual demand in season $k$ decreasing by $\rho$

As shown above, $m, j, k, S, D, D_{k}, d_{j k}, P, n_{j k}, q_{j}, Q_{k}$ $H_{v}, H_{b j}, C_{o}, C_{s}, C_{d}, C_{t}, P_{c}, S_{p}, L, F, \rho, \alpha_{k}, \beta_{k}$ and $\gamma_{k}$ are all 25 symbols which would be used in the model.

\subsection{Assumptions}

In order to establish a feasible model, several assumptions have to be introduced:

1. The production in one period is greater than the demand $\left(\mathrm{p} \geq \sum_{j=1}^{m} d_{j k}\right)$.

2. The ordering cost per order and transportation cost per shipment for each buyer are the same.

3 . The number of the shipments in one period is equal for each buyer, while the size of which might be different.

4. Holding cost and ordering cost are equal for each buyer.

5. The quantity of safety stock is equal for each buyer.

6 . The system only consists of a single type of item.

7. The time costs generated by subcontracting could be ignored.

8. The total demand for all buyers of the whole year is divided into 4 parts. That is, $\mathrm{D}=$ $\sum_{k=1}^{4} \sum_{j=1}^{m} d_{j k}$, where $d_{j k}$ is the demand for buyer $\mathrm{j}$ in season $\mathrm{k}$.

9. All buyers' sales volume during the leading time is normally distributed.

10. All buyers have the same standard variance $(\mathrm{F})$ during the leading time

11. Transportation cost will be borne by buyers.

12. $\mathrm{m}, n_{j k}$ and $Q_{k}$ are decision variables.

13. $n_{k} \geq 1 ; Q_{k} \geq 0 ; Q_{k} \leq D_{k} ; \mathrm{m} \geq 1 ; n_{k}, \mathrm{~m}$ and $D_{k} / Q_{k}$ are integers. 


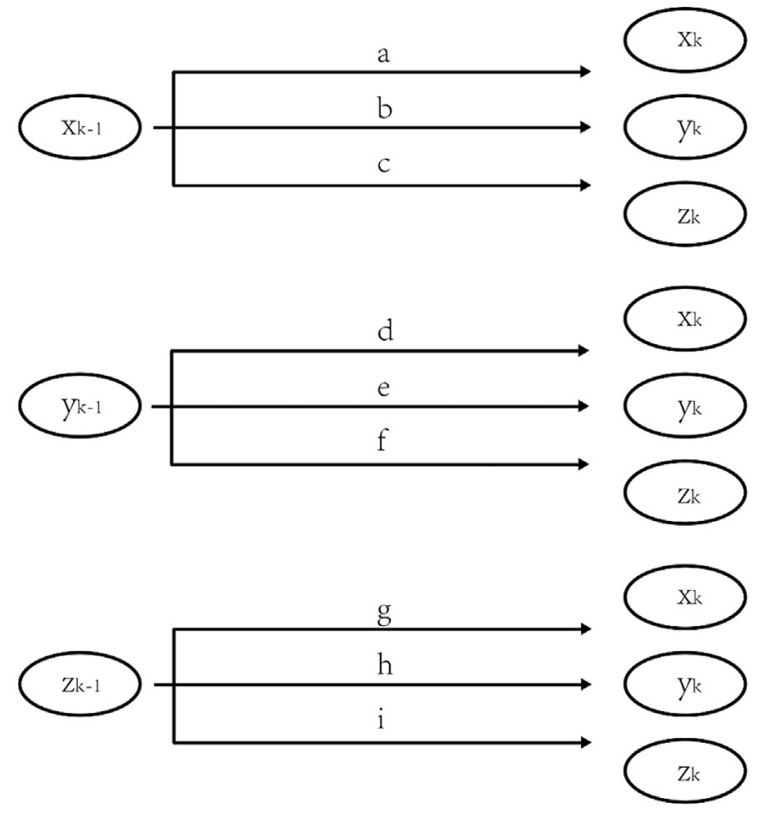

Fig. 1. The schematic diagram of Markov Chain.

14. Suppose that the demand in season $\mathrm{k}$ would be influenced by the demand in the same season last year. For example, if the practical demand in season $k$ last year, compared with the forecasting demand, increased by $\rho$, the possibility for the demand in the same season this year of increasing by $\rho$ would be $\alpha_{k 1}$, remaining unchanged would be $\beta_{k 1}$ and decreasing by $\rho$ would be $\gamma_{k 1}$. By parity of reasoning, all situations can be represented as the following matrix and Fig. 2:

For season $\mathrm{k}:\left[\begin{array}{lll}\alpha_{k 1} & \beta_{k 1} & \gamma_{k 1} \\ \alpha_{k 2} & \beta_{k 2} & \gamma_{k 2} \\ \alpha_{k 3} & \beta_{k 3} & \gamma_{k 3}\end{array}\right]\left[\alpha_{k} \beta_{k} \gamma_{k}\right]=\left[\begin{array}{lll}\alpha_{k} & \beta_{k} & \gamma_{k}\end{array}\right]$

As shown above, these are the 14 assumptions on which the new model is built.

\subsection{Basic model}

The vendor's inventory level against time is shown as follows. The step-by-step derivation of the function of vender's inventory is given in Appendix 2.

From Fig. 3, the area of the triangle LKO in one period in season $\mathrm{k}$ is given by

$=\frac{Q_{k}}{2 P}\left(Q_{k}=\sum_{j=1}^{m} n_{j k} q_{j}\right)$

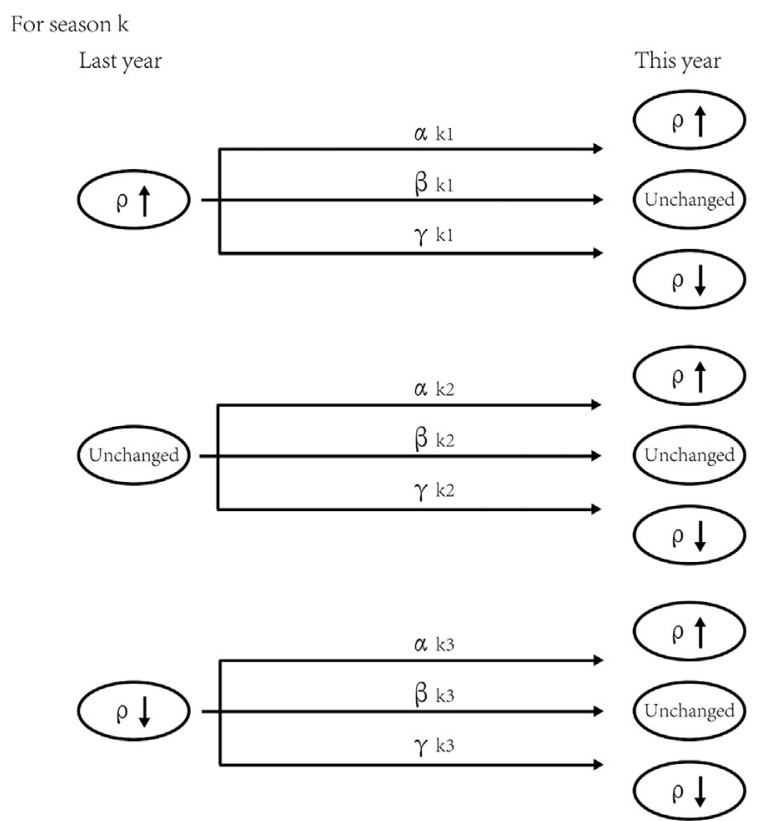

Fig. 2. The schematic diagram of Markov Chain applying in the model.

The area of the rectangle LONM in one period in season $\mathrm{k}$ is given by

$$
\begin{gathered}
=\left(Q_{k}=\sum_{j=1}^{m} n_{j k} q_{j}\right) \sum_{j=1}^{m}\left(\frac{Q_{k}}{d_{j k}}-\frac{Q_{k}}{P}-\frac{Q_{k}}{d_{j k} n_{1 k}}+\frac{Q_{k} d_{1 k}}{d_{j k} P n_{1 k}}\right) \\
=Q_{k} \sum_{j=1}^{m}\left(\frac{Q_{k}}{d_{j k}}-\frac{Q_{k}}{P}-\frac{Q_{k}}{d_{j k} n_{1 k}}+\frac{Q_{k} d_{1 k}}{d_{j k} P n_{1 k}}\right) \\
=\frac{Q_{k}^{2}}{P} \sum_{j=1}^{m} \frac{P n_{1 k}-d_{j k} n_{1 k}-P+d_{1 k}}{d_{j k} n_{1 k}}
\end{gathered}
$$

The area of rectangles (The darker part in the schematic diagram shown in Fig. 3) for each buyer in one period in season $\mathrm{k}$ is as follows:

For buyer $\mathrm{j}$, the area of the rectangle

$$
\begin{aligned}
= & \frac{Q_{k} d_{j k}}{n_{j k} D_{k}}\left(\frac{Q_{k}}{n_{j k} D_{k}}\left(n_{j k}-1\right)+\frac{Q_{k}}{n_{j k} D_{k}}\left(n_{j k}-2\right)+\frac{Q_{k}}{n_{j k} D_{k}}\left(n_{j k}-3\right)\right. \\
& \left.+\ldots+\frac{Q_{k}}{n_{j k} D_{k}}\right)+n_{j k}\left(\frac { Q _ { k } d _ { j k } } { n _ { j k } D _ { k } } \left(\frac{Q_{k}}{n_{1 k} D_{k}}\left(n_{1 k}-1\right)\right.\right. \\
& \left.\left.-\frac{Q_{k}}{n_{j k} D_{k}}\left(n_{j k}-1\right)+\frac{Q_{k} d_{1 k}}{P n_{1 k} D_{k}}-\sum_{i=1}^{j} \frac{Q_{k} d_{i k}}{P n_{i k} D_{k}}\right)\right) \\
= & \frac{Q_{k}^{2} d_{j k}}{D_{k}^{2}}\left(\frac{n_{j k}-1}{2 n_{j k}}+\frac{n_{1 k}-1}{n_{1 k}}-\frac{n_{j k}-1}{n_{j k}}+\frac{d_{1 k}}{P n_{1 k}}-\sum_{i=1}^{j} \frac{d_{i k}}{P n_{i k}}\right)
\end{aligned}
$$

$=\frac{Q_{k}^{2}}{2 P}$ 
For all buyers in one period in season $\mathrm{k}$.

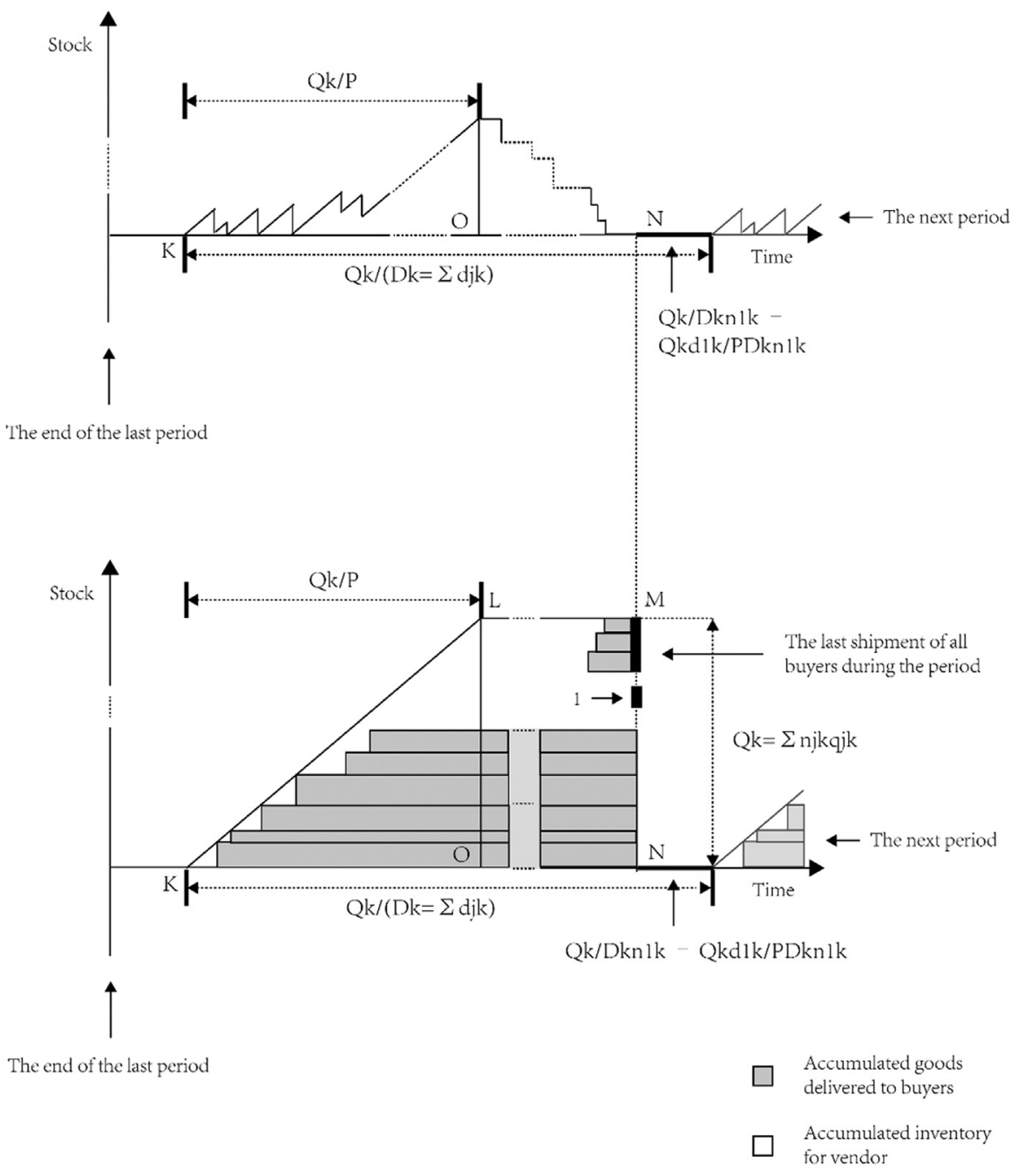

Fig. 3. This schematic diagram shows vendor's inventory level against time. The grey part in the first diagram shows the level of accumulated inventory for vendors while the darker part in the second diagram represents the quantity of goods delivered to buyers.

$=\frac{Q_{k}^{2} d_{j k}}{2 D_{k}^{2} P}\left(\frac{2 n_{j k}\left(P\left(n_{1 k}-1\right)+d_{1 k}-n_{1 k} \sum_{i=1}^{j} \frac{d_{i k}}{n_{i k}}\right)-P n_{1 k}\left(n_{j k}-1\right)}{n_{1 k} n_{j k}}\right)$

The sum of the area of rectangles for all buyers in one period in season $\mathrm{k}$ is given by: 


$$
=\frac{Q_{k}^{2}}{2 D_{k}^{2} P}\left(\sum_{j=1}^{m} d_{j k} \frac{2 n_{j k}\left(P\left(n_{1 k}-1\right)+d_{1 k}-n_{1 k} \sum_{i=1}^{j} \frac{d_{i k}}{n_{i k}}\right)-P n_{1 k}\left(n_{j k}-1\right)}{n_{1 k} n_{j k}}\right)
$$

According to Fig. 3, vendor's average inventory is given by:

$$
\begin{gathered}
=\frac{E q \cdot(1)+E q \cdot(2)-E q \cdot(3)}{Q_{k} / D_{k}} \\
=\frac{D_{k}}{Q_{K}}\left(\frac{Q_{k}^{2}}{2 P}+\frac{Q_{k}^{2}}{P} I_{A}-\frac{Q_{k}^{2}}{2 D_{k}^{2} P} I_{B}\right) \\
=\frac{Q_{k}}{2 P D_{k}}\left(D_{k}^{2}+2 D_{k}^{2} I_{A}-I_{B}\right)
\end{gathered}
$$

where

$I_{A}=\sum_{j=1}^{m} \frac{P n_{1 k}-d_{j k} n_{1 k}-P+d_{1 k}}{d_{j k} n_{1 k}}$
Since vendor's total cost in season $\mathrm{k}$ includes the setup, holding cost, subcontracting cost and disposing cost, vendor's total cost in season $\mathrm{k}$ is obtained as follows:

$$
\begin{aligned}
& =\text { Eq.(7) }+ \text { Eq.(8) }+ \text { Eq.(9) }+ \text { Eq. (10) } \\
& =\mathrm{S} \frac{D_{k}}{Q_{k}}+\frac{H_{v}}{2 P}\left(D_{k}{ }^{2}+2 D_{k}{ }^{2} I_{A}-I_{B}\right)+\rho C_{s} \alpha_{k} D_{k}+\rho C_{d} \gamma_{k} D_{k}
\end{aligned}
$$

Vendor's total cost in one year is

$$
=\sum_{k=1}^{4}\left(S \frac{D_{k}}{Q_{k}}+\frac{H_{v}}{2 P}\left(D_{k}^{2}+2 D_{k}^{2} I_{A}-I_{B}\right)+\rho C_{s} \alpha_{k} D_{k}+\rho C_{d} \gamma_{k} D_{k}\right)
$$

$I_{B}=\sum_{j=1}^{m} d_{j k} \frac{2 n_{j k}\left(P\left(n_{1 k}-1\right)+d_{1 k}-n_{1 k} \sum_{i=1}^{j} \frac{d_{i k}}{n_{i k}}\right)-P n_{1 k}\left(n_{j k}-1\right)}{n_{1 k} n_{j k}}$

\subsubsection{Vendor's total cost}

In this model, vendor's total cost in season $\mathrm{k}$ includes the setup cost, holding cost, subcontracting cost and disposing cost.

Setup cost in season $\mathrm{k}=\mathrm{S} \frac{\sum_{j=1}^{m} d_{j k}}{Q_{k}}$

According to Eq. (4), vendor's holding cost in season $\mathrm{k}$ is given by

$$
\begin{aligned}
& =H_{v} \frac{Q_{k}}{2 P D_{k}}\left(D_{k}^{2}+2 D_{k}^{2} I_{A}-I_{B}\right) \frac{D_{k}}{Q_{k}} \\
& =\frac{H_{v}}{2 P}\left(D_{k}^{2}+2 D_{k}^{2} I_{A}-I_{B}\right)
\end{aligned}
$$

Vendor's subcontracting cost in season $\mathrm{k}=\rho C_{s} \alpha_{k} D_{k}$

Vendor's disposing cost in season $\mathrm{k}=\rho C_{d} \gamma_{k} D_{k}$

\subsubsection{Buyers' total cost}

Since buyers' total cost in season $\mathrm{k}$ includes holding cost, ordering cost, and transportation cost, the process of deduction could be shown as follows.

Every buyer's inventory level against time is illustrated in the following schematic diagram.

Since buyers' safety stock is normally distributed, as demonstrated to Fig. 4,

buyer $j$ 's average inventory $=\frac{q_{j}}{2}+F \sigma \sqrt{L}$

where $\sigma$ is the confidence level.

Buyer j's holding cost $=H_{b j}\left(\frac{q_{j}}{2}+F \sigma \sqrt{L}\right)$

Buyers' holding cost in season

$$
\mathbf{k}=\sum_{j=1}^{m}\left(H_{b j}\left(\frac{q_{j}}{2}+F \sigma \sqrt{L}\right)\right)
$$


For all buyers in one period in season $\mathrm{k}$.

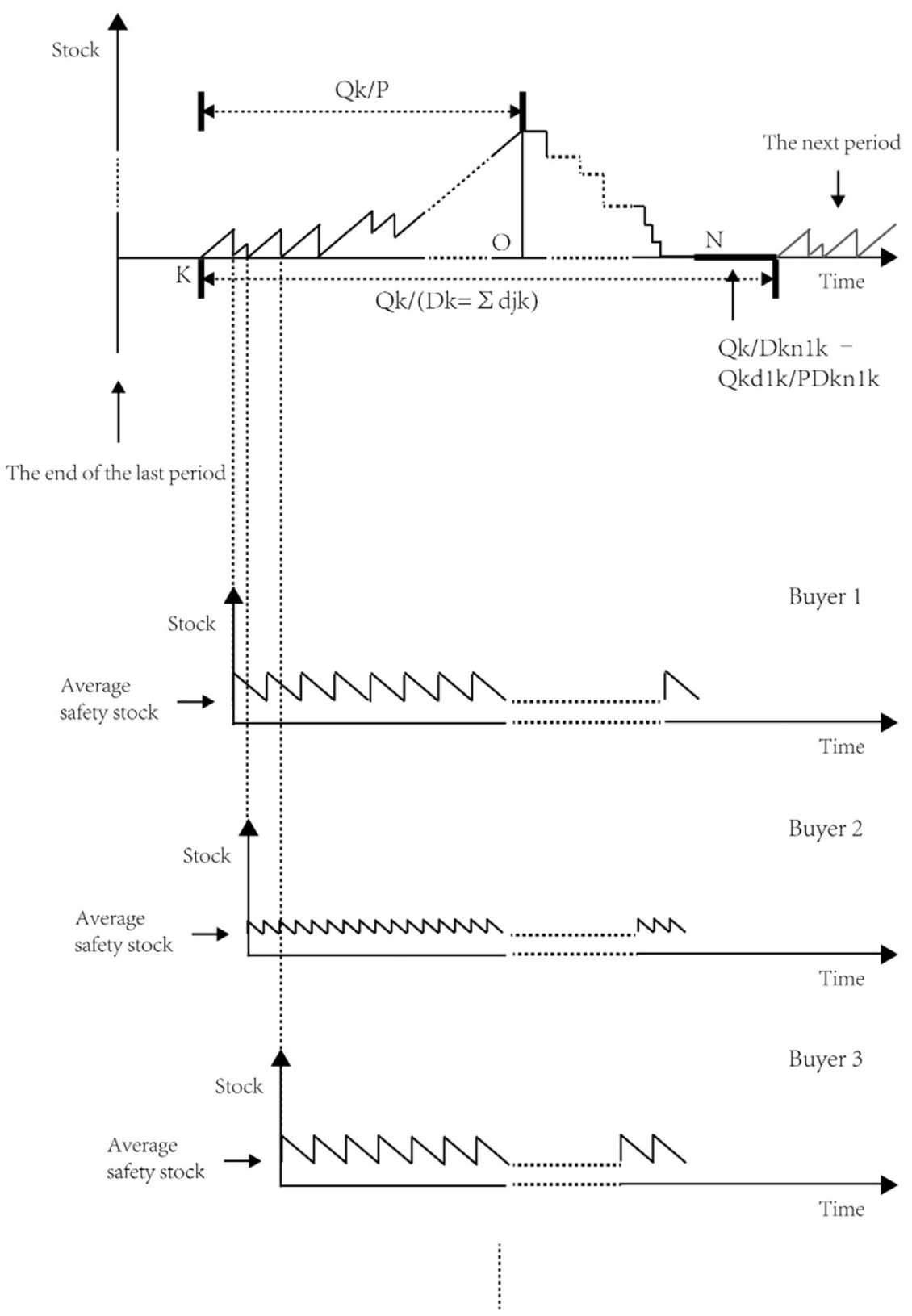

Fig. 4. This schematic diagram shows buyers' inventory level against time respectively.

Buyers' ordering cost in season $\mathrm{k}=\frac{C_{o} m D_{k}}{Q_{k}}$

Transportation cost in season $\mathrm{k}=C_{t} \frac{D_{k}}{Q_{k}} \sum_{j=1}^{m} n_{j k}$

Since buyers' total cost in season $\mathrm{k}$ consists of holding cost, ordering cost, transportation cost, buyers' total cost in season $\mathrm{k}$

$$
=\sum_{j=1}^{m} H_{b j}\left(\frac{q_{j}}{2}+F \sigma \sqrt{L}\right)+\frac{C_{o} m D_{k}}{Q_{k}}+C_{t} \sum_{j=1}^{m} n_{j k}
$$

$=$ Eq. $(15)+$ Eq.(16) + Eq.(17)
Buyers' total cost in one year

$$
=\sum_{k=1}^{4}\left(\sum_{j=1}^{m}\left(H_{b j}\left(\frac{q_{j}}{2}+F \sigma \sqrt{L}\right)\right)+\frac{C_{o} m D_{k}}{Q_{k}}+C_{t} \frac{D_{k}}{Q_{k}} \sum_{j=1}^{m} n_{j k}\right)
$$


Table 1. The incidence of three different conditions in season $k$.

\begin{tabular}{|c|c|c|c|c|c|c|}
\hline & Season 1 & & & Season 2 & & \\
\hline The condition of the last season & $\alpha_{\mathrm{k}}$ & $\beta_{\mathrm{k}}$ & $\gamma_{k}$ & $\alpha_{\mathrm{k}}$ & $\beta_{\mathrm{k}}$ & $\gamma_{\mathrm{k}}$ \\
\hline \multirow[t]{2}{*}{$\begin{array}{l}\text { The incidence of three different } \\
\text { conditions this season }\left(\alpha_{\mathrm{k}} / \beta_{\mathrm{k}} / \gamma\right)\end{array}$} & $0.05 / 0.94 / 0.01$ & $0.01 / 0.97 / 0.02$ & $0.01 / 0.95 / 0.04$ & $0.04 / 0.94 / 0.02$ & $0.02 / 0.96 / 0.02$ & $0.02 / 0.95 / 0.03$ \\
\hline & Season 3 & & & Season 4 & & \\
\hline The condition of the last season & $\alpha_{\mathrm{k}}$ & $\beta_{\mathrm{k}}$ & $\gamma_{\mathrm{k}}$ & $\alpha_{\mathrm{k}}$ & $\beta_{\mathrm{k}}$ & $\gamma_{\mathrm{k}}$ \\
\hline $\begin{array}{l}\text { The incidence of three different } \\
\text { conditions this season }\left(\alpha_{k} / \beta_{k} / \gamma\right)\end{array}$ & $0.05 / 0.93 / 0.02$ & $0.01 / 0.98 / 0.01$ & $0.01 / 0.94 / 0.05$ & $0.03 / 0.95 / 0.02$ & $0.02 / 0.97 / 0.01$ & $0.02 / 0.93 / 0.05$ \\
\hline
\end{tabular}

$\alpha_{\mathrm{k}}$ : Possibility of the actual demand in season $\mathrm{k}$ increasing by. $\rho$

$\beta_{\mathrm{k}}$ : Possibility of the actual demand in season $\mathrm{k}$ is exactly same as the expected demand.

$\gamma_{k}$ : Possibility of the actual demand in season $k$ decreasing by. $\rho$

Table 2. The constant incidence of three different conditions in season $k$.

\begin{tabular}{llll}
\hline & $\alpha_{\mathrm{k}}$ & $\beta_{\mathrm{k}}$ & $\gamma_{\mathrm{k}}$ \\
\hline Season 1 & 0.0104 & 0.9693 & 0.0203 \\
Season 2 & 0.0204 & 0.9594 & 0.0202 \\
Season 3 & 0.0104 & 0.9791 & 0.0105 \\
Season 4 & 0.0202 & 0.9692 & 0.0106 \\
\hline
\end{tabular}

\subsubsection{The total profit}

To determine the function of the total profit of the system, it is quite essential to calculate total cost accurately. In this model, the total cost includes vendor's total cost, buyers' total cost and production cost. The vendor's total cost and buyers' total cost have already been shown in previous sections.

Production $\cos \mathrm{t}=P_{c} \sum_{k=1}^{4} D_{k}$

Thus, total cost $=$ vendor's total cost in one year + buyers' total cost in one year + production cost

$$
\begin{aligned}
& =\mathrm{Eq} \cdot(12)+\mathrm{Eq} \cdot(19)+\mathrm{Eq} \cdot(20) \\
& =\sum_{k=1}^{4}\left(S \frac{D_{k}}{Q_{k}}+\frac{H_{v}}{2 P}\left(D_{k}{ }^{2}+2 D_{k}{ }^{2} I_{A}-I_{B}\right)+\rho C_{s} \alpha_{k} D_{k}\right. \\
& \quad+\rho C_{d} \gamma_{k} D_{k}+\sum_{j=1}^{m}\left(H_{b j}\left(\frac{q_{j}}{2}+F \sigma \sqrt{L}\right)\right)+\frac{C_{o} m D_{k}}{Q_{k}} \\
& \left.\quad+C_{t} \sum_{j=1}^{m} n_{j k}+P_{c} D_{k}\right)
\end{aligned}
$$

Total revenue $=S_{p} \sum_{k=1}^{4} D_{k}$

Since profit is equal to revenue subtract cost,

\begin{tabular}{|c|c|c|c|c|}
\hline Season & $1^{s t}$ & $2^{n d}$ & $3^{r d}$ & $4^{\text {th }}$ \\
\hline Demand $D_{k}$ & mx900 units/buyer & mx1000 units/buyer & mx1200 units/buyer & mx600 units/buyer \\
\hline Setup cost $S$ & $300 \$$ & & & \\
\hline Production $P$ & 5000 units/season & & & \\
\hline Vendor's holding cost $H_{v}$ & 5 \$/unit/season & & & \\
\hline Buyers' holding cost $H_{b j}$ & 2 \$/unit/season & & & \\
\hline Ordering cost $C_{o}$ & $30 \$ /$ period & & & \\
\hline Subcontracting cost $C_{s}$ & 3 \$/unit & & & \\
\hline Disposing cost $C_{d}$ & 4 \$/unit & & & \\
\hline Transportation cost $C_{t}$ & 40 \$/shipment & & & \\
\hline$F$ & 20 units & & & \\
\hline$P$ & $5 \%$ & & & \\
\hline$\alpha_{k}$ & 0.0104 & 0.0204 & 0.0104 & 0.0202 \\
\hline$\beta_{k}$ & 0.9693 & 0.9594 & 0.9791 & 0.9692 \\
\hline$\gamma_{k}$ & 0.0203 & 0.0202 & 0.0105 & 0.0106 \\
\hline$\sigma$ & \multicolumn{4}{|c|}{1.645 (for $95 \%$ confidence) } \\
\hline$L$ & \multicolumn{4}{|c|}{0.05 season } \\
\hline Sale price $S_{p}$ & \multicolumn{4}{|l|}{35 \$/unit } \\
\hline Production cost $P_{c}$ & \multicolumn{4}{|l|}{5 \$/unit } \\
\hline
\end{tabular}
the total profit of the whole system is given by

$$
=\text { Eq. }(22)-\text { Eq. }(21)
$$

Table 3. Values off all parameters.

*According to practical experience, this paper sets the confidence interval in the case as $95 \%$. Thus the confidence level $\sigma$ is 1.645 . 
Table 4. The optimum solution of the case.

\begin{tabular}{lllll}
\hline & Season 1 & Season 2 & Season 3 & Season 4 \\
\hline$Q_{k}$ (unit) & 1800 & 1333.33 & 1600 & 1200 \\
$n_{k}$ (time) & 1 & 1 & 1 & 1 \\
Period (time) & 2 & 3 & 3 & 2 \\
$\mathrm{M}$ & 4 & & & \\
Total profit (\$) & 273112.7 & & & \\
\hline
\end{tabular}

$$
\begin{gathered}
=S_{p} \sum_{k=1}^{4} D_{k}-\sum_{k=1}^{4}\left(S \frac{D_{k}}{Q_{k}}+\frac{H_{v}}{2 P}\left(D_{k}^{2}+2 D_{k}^{2} I_{A}-I_{B}\right)\right. \\
+\rho C_{s} \alpha_{k} D_{k}+\rho C_{d} \gamma_{k} D_{k}+\sum_{j=1}^{m}\left(H_{b j}\left(\frac{q_{j}}{2}+F \sigma \sqrt{L}\right)\right) \\
\left.+\frac{C_{o} m D_{k}}{Q_{k}}+C_{t} \frac{D_{k}}{Q_{k}} \sum_{j=1}^{m} n_{j k}+P_{c} D_{k}\right)
\end{gathered}
$$

Where $\mathrm{m}, n_{j k}$ and $Q_{k}$ are decision variables.

\subsection{The algorithm}

Hans Siajadi [8] and Jhih Ping Lin [16] adopted the integrated inventory model to obtain optimal benefits of the whole system. Based on that, this paper uses Markov Chain to optimize the model.

The algorithm is shown as follows.

Step 1. Use the spirit of Markov Chain to forecast future demand. The derivation is given in appendix 3.

Step 2. Substitute all data into the objective function.

Step 3. Determine the second partial derivatives of the objective function.

Step 4. Determine the optimum solution of the case so that the highest value of the objective functions can be obtained.

According to the actual situation, decision makers can determine the confidence interval to the safety

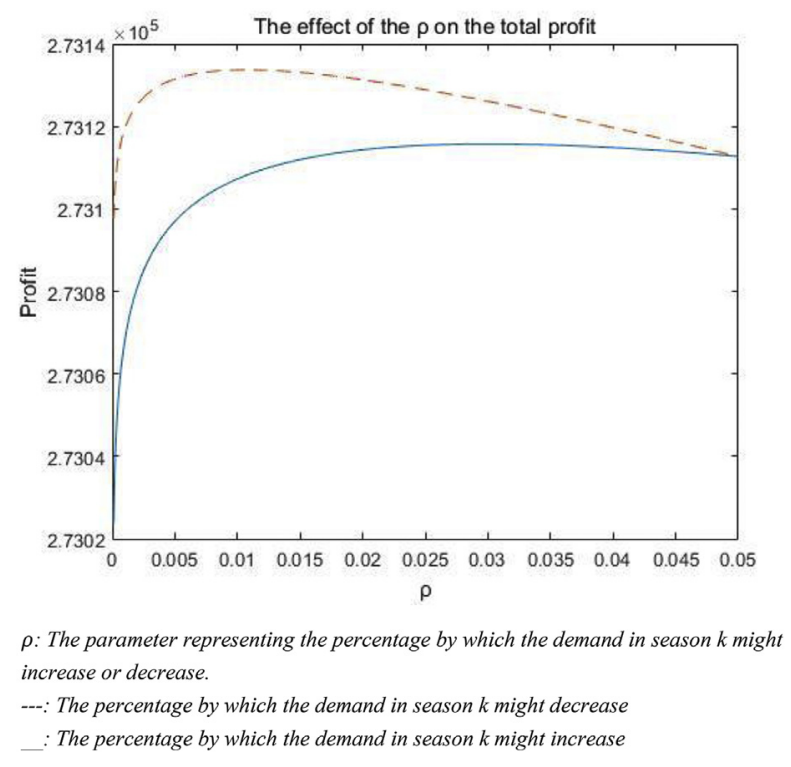

Fig. 5. The effect of the $\rho$ on the total profit.

stock by themselves to make the most efficient strategies for their companies. The confidence level $\sigma$ will change with the confidence internal, a result in the change of the optimal solution of the whole system.

To explain the new model more effectively and efficiently, an example of the solution is given in the next section.

\section{Case study}

In order to prove the feasibility and practicability of the new model, as well as explaining the usage of the new model much more distinctly, a practical case is developed as follows.

\subsection{Numerical illustration}

Table 3 shows the values of all parameters in this case.

From Table 3, we substitute the values into Eq. (5), Eq. (6) and Eq. (20):

The total cost

Table 5. The effect of parameters changes on the increase of the total profit.

\begin{tabular}{llllll}
\hline Parameter & $\mathrm{S}$ & $H_{v}$ & $H_{b}$ & $C_{o}$ & $C_{t}$ \\
\hline The total profit $+1 \%$ & $-91.3 \%$ & $-1.8 \%$ & $-44.5 \%$ & $-227.6 \%$ & $-170.7 \%$ \\
\hline
\end{tabular}




$$
\begin{aligned}
= & \sum_{k=1}^{4}\left(300 \frac{D_{k}}{Q_{k}}+\frac{1}{2000}\left(D_{k}^{2}+2 D_{k}^{2} \sum_{j=1}^{m} \frac{5000 n_{k}-d_{j k} n_{k}-5000+d_{j k}}{d_{j k} n_{k}}-\sum_{j=1}^{m} d_{j k} \frac{5000\left(n_{k}-1\right)+2 d_{j k}-2 n_{k} \sum_{i=1}^{j} \frac{d_{j k}}{n_{k}}}{n_{k}}\right)\right. \\
& \left.+0.15 \alpha_{k} D_{k}+0.2 \gamma_{k} D_{k}+\frac{Q_{k}}{n_{k}}+2 m F \sigma \sqrt{L}+\frac{30 m D_{k}}{Q_{k}}+40 \frac{D_{k}}{Q_{k}} \mathrm{~m} n_{k}\right)
\end{aligned}
$$

\subsection{The optimum solution}

From Eq. (24), the total profit is given by: influenced by changes in the given parameters $\rho, S$, $H_{v}, H_{b}, C_{o}$ and $C_{t}$ and the feasible way to cut the cost of the supply chain system.

$$
\begin{aligned}
= & \sum_{k=1}^{4}\left(30 D_{k}-\left(300 \frac{D_{k}}{Q_{k}}+\frac{1}{2000}\left(D_{k}^{2}+2 D_{k}^{2} \sum_{j=1}^{m} \frac{5000 n_{k}-d_{j k} n_{k}-5000+d_{j k}}{d_{j k} n_{k}}\right.\right.\right. \\
& \left.\left.\left.-\sum_{j=1}^{m} d_{j k} \frac{5000\left(n_{k}-1\right)+2 d_{j k}-2 n_{k} \sum_{i=1}^{j} \frac{d_{j k}}{n_{k}}}{n_{k}}\right)+0.15 \alpha_{k} D_{k}+0.2 \gamma_{k} D_{k}+\frac{Q_{k}}{n_{k}}+2 m F \sigma \sqrt{L}+\frac{30 m D_{k}}{Q_{k}}+40 \frac{D_{k}}{Q_{k}} \mathrm{~m} n_{k}\right)\right)
\end{aligned}
$$

The schematic diagram of the function is given in appendix 4 .

The optimal solution of the case is illustrated in Table 4:

From Table 4, we substitute all the values in Eq. (25), the maximal value of the system's profit is \$273112.7.

\subsection{Sensitivity analysis}

In the previous section, the optimum solution of the practical case has already been found. In the reality, however, in order to improve customers' satisfaction and achieve the goal of sustainable development, decision makers still have to develop a feasible plan to optimize the supply chain system. In this section, a sensitivity analysis is perfomed to find out how the out put into the model could be

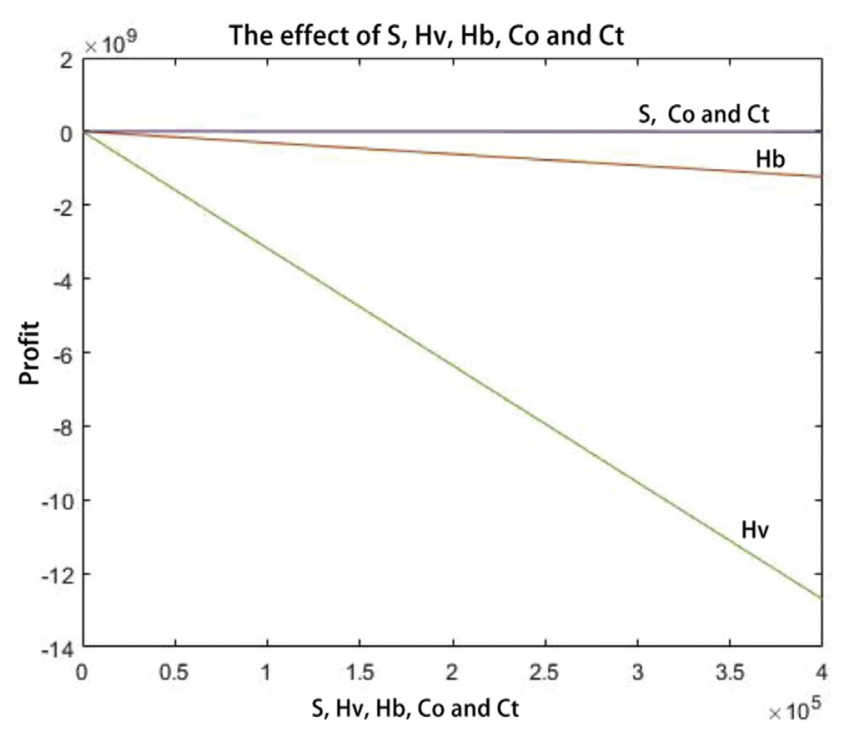

Fig. 6. The relationships between the total profits and parameters $S, H_{v}$, $H_{b}, C_{o}$ and $C_{t}$. 
1. Suppose that with every $10 \$$ be invested into the system, the percentage by which the demand in season $\mathrm{k}$ might increase would decrease by $10 \%$, and with every $5 \$$ be invested into the system, the percentage by which the demand in season $\mathrm{k}$ might decrease would decrease $10 \%$. As indicated in Fig. 5, if the percentage by which the demand in season $\mathrm{k}$ might increase is the only parameter to be considered, it is quite easy to find out that when $\rho$ decreases to 0.03 , the system would have the highest profit of $273115.7 \$$. If the percentage by which the demand in season $\mathrm{k}$ might decrease is the only parameter to be considered, the system would have the highest profit of $273133.7 \$$ when $\rho$ decreases to 0.011 .

2. Table 5 illustrates that in order to make the total profit increase by $1 \%$, setup cost (S) is supposed to decrease by $91.3 \%$, which means that only as the setup cost approaches 0 , could the total profit increase obviously. In other words, it is quite hard for decision makers to gain higher profits by cutting down the setup cost.

3. Table 5 illustrates that in order to make the total profit increase by $1 \%$, vendor's holding cost $\left(H_{v}\right)$ is supposed to decrease by $-1.8 \%$. Since the ratio of the increasing rate of the total profit and the decreasing rate of the vendor's holding cost is close to -1 , as the vendor's holding cost falls, the total profit would increase rapidly.

4. Table 5 illustrates that in order to make the total profit increase by $1 \%$, buyers' holding cost $\left(H_{b}\right)$ is supposed to decrease by $44.5 \%$. Which means that as buyers' holding cost falls, the total profit would slowly increase.

5. Table 5 illustrates that in order to make the total profit increase by $1 \%$, ordering cost $\left(C_{o}\right)$ is supposed to decrease by $227.6 \%$. Since the decreasing rate of the ordering cost is even higher than $100 \%$, it is quite impossible for decision makers to gain higher profits by reducing the ordering cost.

6. Table 5 illustrates that in order to make the total profit increase by $1 \%$, transportation cost $\left(C_{t}\right)$ is supposed to decrease by $-170.7 \%$. Just like the decreasing rate of the ordering cost, the decreasing rate of the transportation cost is quite high-even higher than $100 \%$. Thus, it is impossible for decision makers to gain higher profits by reducing the transportation cost.

The relationships between the total profits and five cost parameters $\left(\mathrm{S}, H_{v}, H_{b}, C_{o}\right.$ and $\left.C_{t}\right)$ is presented clearly in Fig. 6, where the rate of change in the total profits relatives to $\mathrm{S}, H_{v}, H_{b}, C_{o}$ and $C_{t}$ is shown respectively.

The sensitivity analysis of the given parameters $\rho$, $\mathrm{S}, H_{v}, H_{b}, C_{o}$ and $C_{t}$ is shown as above. The feasible way of adjusting these parameters to help the system achieve a higher profit will be introduced in the next section.

\section{Conclusions}

This study makes potential contributions to the literature. First, we discuss the issue of the onevendor and multiple-buyers integrated inventory model with Markov chain demands to forecast the fluctuation of future demand. Then, we determined the optimal solution for decision makers to reduce the total cost of the whole supply chain system. Finally, we provide the systematic-model that consider the fluctuating prospective demand to support decision makers seeking to gain maximum profits in real-world businesses.

Through case analysis, we can find out that when the numbers of periods occurred in four seasons are 2, 3, 3 and 2 respectively, the quantities of demands per period for all buyers in four seasons are 1800 units, 1333.33 units, 1600 units and 1200 units correspondingly, and the number of buyers is 4 , the whole system can reach its optimum profit of \$273112.7. However, nowadays, shortages and overages of goods often occur in a supply chain, leading to much higher costs. Thus the significance of optimizing the supply chain system has to be thoroughly understood by decision makers, who should never be satisfied with the existing strategy.

Meanwhile, according to the real situation, it is quite difficult for companies to the total cost by increasing the price of their goods. However, compared to other sections, the cost of supply chain (vendor and buyer's holding cost, ordering cost, subcontracting cost, disposing cost, transportation cost and etc.) is easier to control. Thus, if companies want to enhance their profits, controlling some of those costs and reducing them efficiently is an effective approach for them. According to Fig. 6 and Table 5 , parameters $\rho, \mathrm{S}, H_{v}, H_{b}, C_{o}$ and $C_{t}$ all have certain influence on the total profit in the case study. As indicated in Table 5, the obtained savings increased rapidly as the holding costs, especially the vendor's holding cost, fell. In other words, among the parameters, as the vendor's holding cost falls, the total profit has the highest increasing rate. Thus, in practice, decision makers can use the same way to find out the specific cost they must reduce in their 
Suppose that there are only two buyers.

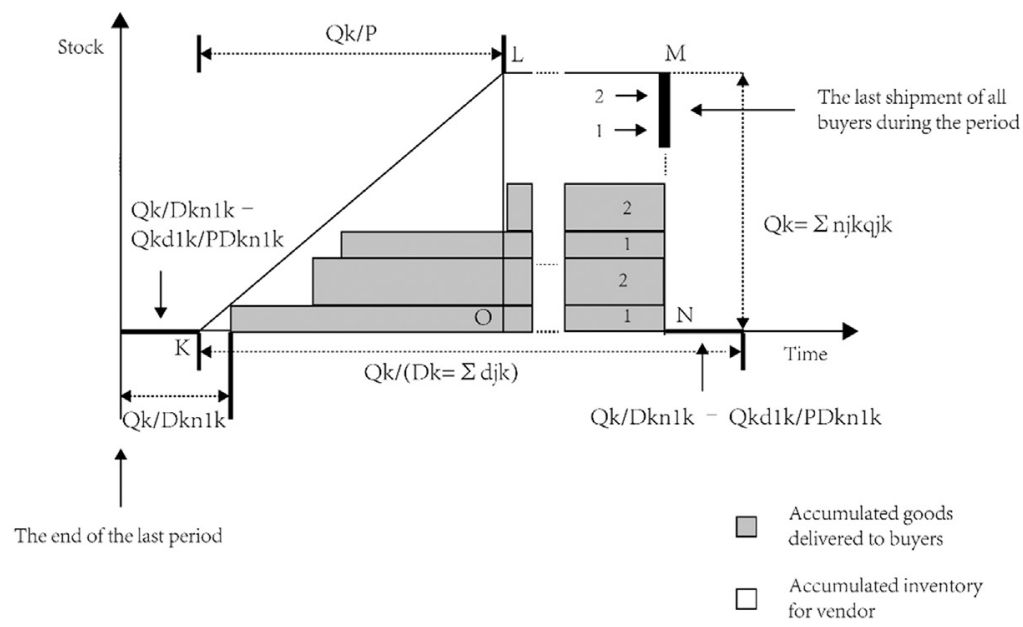

Fig. 7. This schematic diagram shows vendor's inventory level against time when there are only two buyers in the supply chain system. The darker part in the diagram represents the quantity of goods delivered to buyers.

supply chain systems, which can help companies improve profits in the most effective and efficient way.

Obviously, the issue of controlling the demand fluctuation can facilitate companies reduce the total cost. The data analysis revealed that when the percentage by which the demand in season $k$ might increase, decreases to 0.03 , the system would have the highest profit of $\$ 273133.7$. Then, when the percentage, by which the demand in season $\mathrm{k}$ might decrease, decreases to 0.011 , the system would have the highest profit of \$273133.7. Nevertheless, compared to reducing vendor's holding cost, controlling the demand fluctuation is quite inefficient in enhancing companies' profits.

In the preceding discussion suggests increasing the total profit to a specific level in the case mentioned above, the system have to invest much more money to cut down setup cost (S), buyers' holding cost $\left(H_{b}\right)$, ordering cost $\left(C_{o}\right)$ or

Suppose that there are only two buyers.

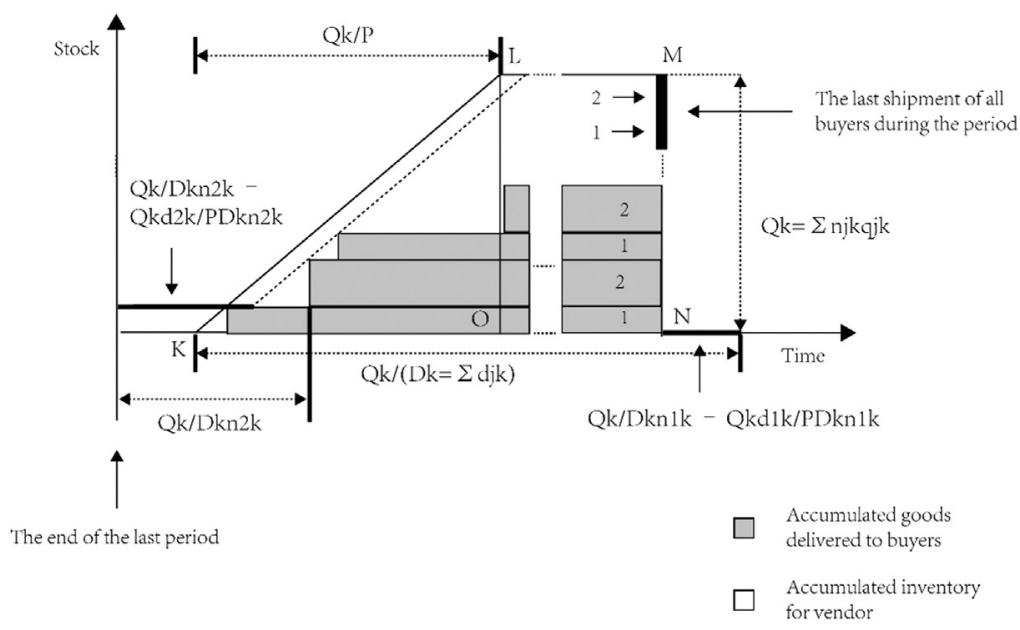

Fig. 8. Suppose the interval between two lots is constant, vendor's inventory level against time could be illustrated as above. 


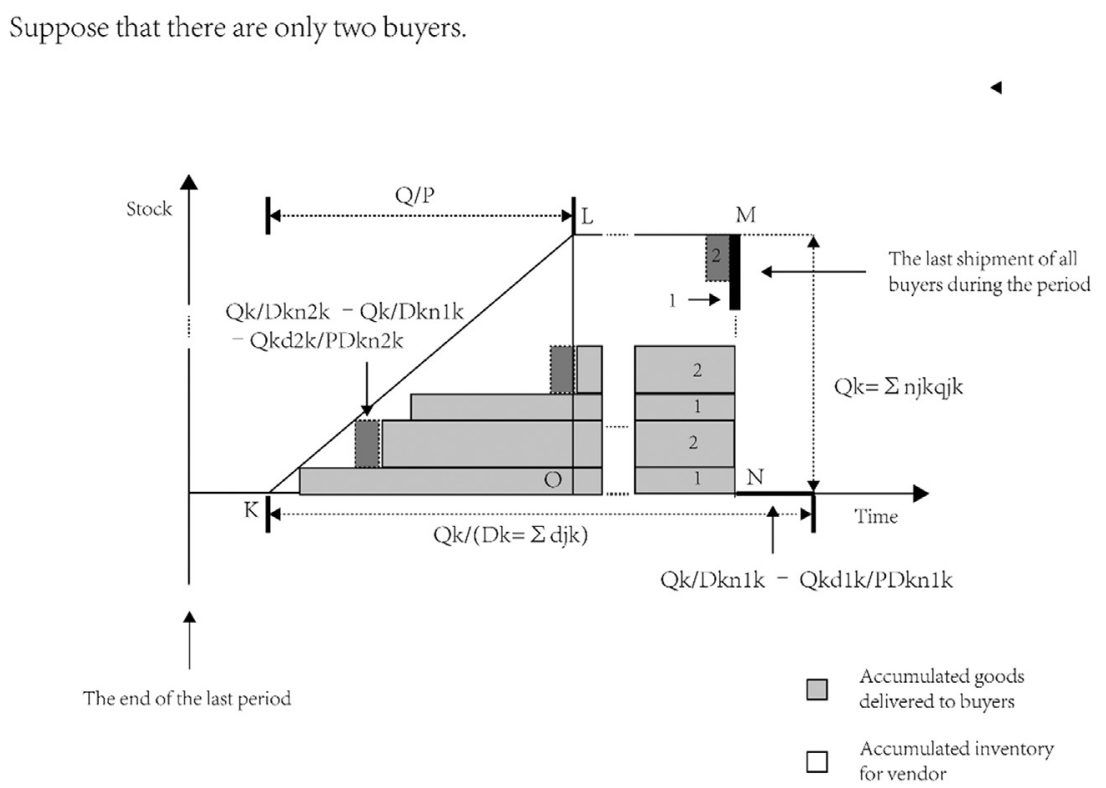

Fig. 9. In practice, the first lot of goods would always be sent to buyers as soon as they are produced, ignoring the interval between two lots.

transportation cost $\left(C_{t}\right)$ than just cutting down vendor's holding cost $\left(H_{v}\right)$. In $C_{o}$ 's case, even if decision makers make a great effort turning $C_{o}$ into 0 , the total profits would not increase by more than $1 \%$. Meanwhile, by reducing $H_{v}$ by only $2 \%$, decision makers can increase the system's total profit by more than $1 \%$.Thus, it is quite obvious that under a limited budget, cutting down the vendor's holding cost is the most feasible and efficient way to optimize the supply chain system and gain a higher profit for the case. In real cases, the very cost of the supply chain system that should be cut down to help the company earns a greater profit may not be the vendor's holding cost $\left(H_{v}\right)$, but the new proposed model discussed by this paper can help decision makers find out the most effective and efficient approach to cut down the supply chain system's total cost and enhance their companies' total profits.

Finally; in future research, we can add more assumptions, considerable elements and equations to forecast the fluctuation of the future demand. In addition, since some of parameters in this paper are fixed while they are actually quite fluctuant in real cases, we will keep improving our further research in more actual word complicities, such as adding the parameter of incidence of freight damage that may happen in transit to destinations. Furthermore, we hope that our research can be extended more realistic to help companies to reach advantages.
We consider the factor of our proposed model has more thoughtful consideration of real-world practical situations. In this study, based on our sensitivity analysis in all parameters, we provide some results which might be helpful for decision-makers. In addition, future research in this direction should also incorporate more real-world complexities and should attempt to develop more refined solution methodologies. Indeed, it is truly hoped that our experimental results are of great interest both for application and related research.

\section{Appendix 1.}

$\mathrm{A}=\left[\begin{array}{lll}a & b & c \\ d & e & f \\ g & h & i\end{array}\right], X_{t}=\left[\begin{array}{lll}x_{t} & y_{t} & z_{t}\end{array}\right] ;$

The schematic diagram of Markov Chain is shown in Fig. 1.

When

$k=1,\left[\begin{array}{lll}a & b & c \\ d & e & f \\ g & h & i\end{array}\right]\left[\begin{array}{lll}x_{0} & y_{0} & z_{0}\end{array}\right]=\left[\begin{array}{lll}x_{1} & y_{1} & z_{1}\end{array}\right]$

$k=2,\left[\begin{array}{lll}a & b & c \\ d & e & f \\ g & h & i\end{array}\right]\left[\begin{array}{lll}x_{1} & y_{1} & z_{1}\end{array}\right]=\left[\begin{array}{lll}x_{2} & y_{2} & z_{2}\end{array}\right]$ 


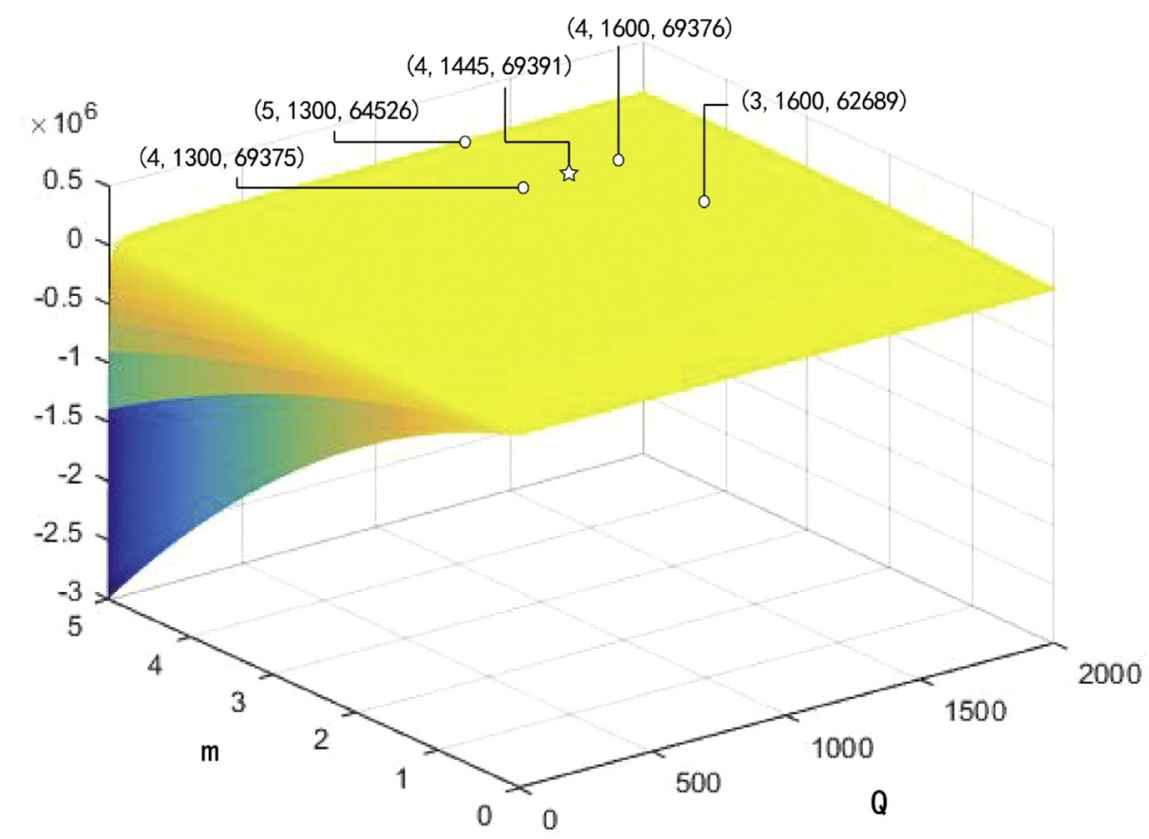

A

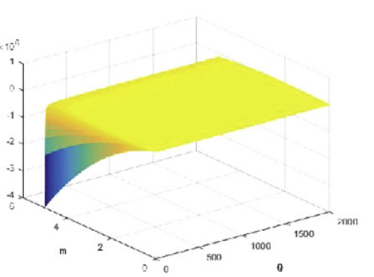

B

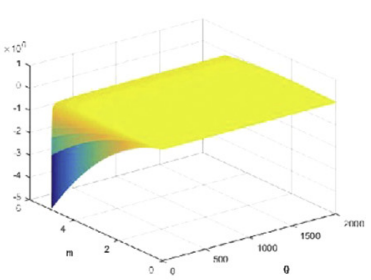

$\mathrm{C}$

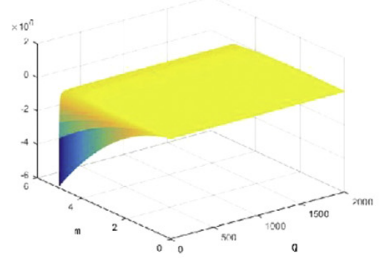

D

Fig. 10. Diagram A, B, C and D represent the schematic diagram of season 1's general function when $n$ equals 1, 2, 3 and 4 respectively.

$k=\ldots ;$

$k=k,\left[\begin{array}{lll}a & b & c \\ d & e & f \\ g & h & i\end{array}\right]\left[\begin{array}{lll}x_{t-1} & y_{t-1} & z_{t-1}\end{array}\right]=\left[\begin{array}{lll}x_{t} & y_{t} & z_{t}\end{array}\right]$

$k=k+1,\left[\begin{array}{lll}a & b & c \\ d & e & f \\ g & h & i\end{array}\right]\left[\begin{array}{lll}x_{t} & y_{t} & z_{t}\end{array}\right]=\left[\begin{array}{lll}x_{t} & y_{t} & z_{t}\end{array}\right]$

$k=\ldots$

Appendix 2.

Firstly, suppose that there are only two buyers in the system.
The area of the rectangle (the darker parts in Fig. 7) for each buyer in one period in season $k$ is shown as follows.

For buyer 1 , the area of the rectangle 1

$$
\begin{gathered}
=\frac{Q_{k} d_{1 k}}{n_{1 k} D_{k}}\left(\frac{Q_{k}}{n_{1 k} D_{k}}\left(n_{1 k}-1\right)+\frac{Q_{k}}{n_{1 k} D_{k}}\left(n_{1 k}-2\right)\right. \\
\left.+\frac{Q_{k}}{n_{1 k} D_{k}}\left(n_{1 k}-3\right)+\ldots+\frac{Q_{k}}{n_{1 k} D_{k}}\right)
\end{gathered}
$$

For buyer 2, the calculating method of the area of the rectangle 2 is introduced as follows.

However, in practice, the first lot of goods would always be sent to buyers as soon as they are produced, ignoring the interval between two lots. The 
schematic diagram of this process is illustrated in

Fig. 9.

According to Fig. 8 and Fig. 9, for buyer 2, the area of the rectangle 2

$$
\left[\begin{array}{lll}
0.05 & 0.94 & 0.01 \\
0.01 & 0.97 & 0.02 \\
0.01 & 0.95 & 0.04
\end{array}\right]\left[\begin{array}{lll}
\alpha_{1} & \beta_{1} & \gamma_{1}
\end{array}\right]=\left[\begin{array}{lll}
\alpha_{1} & \beta_{1} & \gamma_{1}
\end{array}\right]
$$

$$
\begin{aligned}
= & \frac{Q_{k} d_{2 k}}{n_{2 k} D_{k}}\left(\frac{Q_{k}}{n_{2 k} D_{k}}\left(n_{2 k}-1\right)+\frac{Q_{k}}{n_{2 k} D_{k}}\left(n_{2 k}-2\right)+\frac{Q_{k}}{n_{2 k} D_{k}}\left(n_{2 k}-3\right)+\ldots+\frac{Q_{k}}{n_{2 k} D_{k}}\right)+n_{2 k}\left(\frac { Q _ { k } d _ { 2 k } } { n _ { 2 k } D _ { k } } \left(\frac{Q_{k}}{n_{1 k} D_{k}}\left(n_{1 k}-1\right)\right.\right. \\
& \left.\left.-\frac{Q_{k}}{n_{2 k} D_{k}}\left(n_{2 k}-1\right)-\frac{Q_{k} d_{2 k}}{P n_{2 k} D_{k}}\right)\right)
\end{aligned}
$$

The rest may be deduced by analogy.

Thus, for buyer $j$, the area of the rectangle $j$ is

$$
\begin{aligned}
= & \frac{Q_{k} d_{j k}}{n_{j k} D_{k}}\left(\frac{Q_{k}}{n_{j k} D_{k}}\left(n_{j k}-1\right)+\frac{Q_{k}}{n_{j k} D_{k}}\left(n_{j k}-2\right)+\frac{Q_{k}}{n_{j k} D_{k}}\left(n_{j k}-3\right)+\ldots+\frac{Q_{k}}{n_{j k} D_{k}}\right)+n_{j k}\left(\frac { Q _ { k } d _ { j k } } { n _ { j k } D _ { k } } \left(\frac{Q_{k}}{n_{1 k} D_{k}}\left(n_{1 k}-1\right)\right.\right. \\
& \left.\left.-\frac{Q_{k}}{n_{j k} D_{k}}\left(n_{j k}-1\right)+\frac{Q_{k} d_{1 k}}{P n_{1 k} D_{k}}-\sum_{i=1}^{j} \frac{Q_{k} d_{i k}}{P n_{i k} D_{k}}\right)\right) \\
= & \frac{Q_{k}^{2} d_{j k}}{D_{k}^{2}}\left(\frac{n_{j k}-1}{2 n_{j k}}+\frac{n_{1 k}-1}{n_{1 k}}-\frac{n_{j k}-1}{n_{j k}}+\frac{d_{1 k}}{P n_{1 k}}-\sum_{i=1}^{j} \frac{d_{i k}}{P n_{i k}}\right) \\
= & \frac{Q_{k}^{2} d_{j k}}{2 D_{k}^{2} P}\left(\frac{2 n_{1 k}\left(P\left(n_{1 k}-1\right)+d_{1 k}-n_{1 k} \sum_{i=1}^{j} \frac{d_{i k}}{n_{i} k}\right)-P n_{1 k}\left(n_{j k}-1\right)}{n_{1 k} n_{j k}}\right)
\end{aligned}
$$

The sum of the area of rectangles for all buyers in one period in season $\mathrm{k}$ is

$$
=\frac{Q_{k}{ }^{2}}{2 D_{k}{ }^{2} P}\left(\sum_{j=1}^{m} d_{j k} \frac{2 n_{1 k}\left(P\left(n_{1 k}-1\right)+d_{1 k}-n_{1 k} \sum_{i=1}^{j} \frac{d_{i k}}{n_{i}}\right)-P n_{1 k}\left(n_{j k}-1\right)}{n_{1 k} n_{j k}}\right)
$$

\section{Appendix 3.}

Step 1 Use the spirit of Markov Chain to find out the constant possibility of demand increases by $\rho$, remains unchanged and decreases by $\rho$ in season $k$. All parameters are illustrated in Table 1:

According to Table 1, the constant possibility of demand increases by $\rho$, remains unchanged and decreases by $\rho$ in season $\mathrm{k}$ can be shown as Table 2 :

The deviation of Markov chain process is given as follows:

For season 1:

$$
\alpha_{1}=0.0104, \beta_{1}=0.9693, \gamma_{1}=0.0203
$$

For season 2:

$$
\left[\begin{array}{lll}
0.04 & 0.94 & 0.02 \\
0.02 & 0.96 & 0.02 \\
0.02 & 0.95 & 0.03
\end{array}\right]\left[\begin{array}{lll}
\alpha_{2} & \beta_{2} & \gamma_{2}
\end{array}\right]=\left[\begin{array}{lll}
\alpha_{2} & \beta_{2} & \gamma_{2}
\end{array}\right]
$$$$
\alpha_{2}=0.0204, \beta_{2}=0.9594, \gamma_{2}=0.0202
$$

For season 3: 


$$
\begin{aligned}
& {\left[\begin{array}{lll}
0.05 & 0.93 & 0.02 \\
0.01 & 0.98 & 0.01 \\
0.01 & 0.94 & 0.05
\end{array}\right]\left[\begin{array}{lll}
\alpha_{3} & \beta_{3} & \gamma_{3}
\end{array}\right]=\left[\begin{array}{lll}
\alpha_{3} & \beta_{3} & \gamma_{3}
\end{array}\right]} \\
& \alpha_{3}=0.0104, \beta_{3}=0.9791, \gamma_{3}=0.0105
\end{aligned}
$$

For season 4:

$$
\begin{aligned}
& {\left[\begin{array}{lll}
0.03 & 0.95 & 0.02 \\
0.02 & 0.97 & 0.01 \\
0.02 & 0.93 & 0.05
\end{array}\right]\left[\begin{array}{lll}
\alpha_{4} & \beta_{4} & \gamma_{4}
\end{array}\right]=\left[\begin{array}{lll}
\alpha_{4} & \beta_{4} & \gamma_{4}
\end{array}\right]} \\
& \alpha_{4}=0.0202, \beta_{4}=0.9692, \gamma_{4}=0.0106
\end{aligned}
$$

\section{Appendix 4.}

Since the general function of four seasons are almost the same, this article only uses the schematic diagram of season 1 to show that the function has a local maximum point.

According to Fig. 10, the general function of season 1 proved to have a local maximum value. Take the diagram $\mathrm{A}$ for example. Ignoring all constraints $\left(n_{k} \geq 1 ; Q_{k} \geq 0 ; Q_{k} \leq D_{k} ; \mathrm{m} \geq 1 ; n_{k}, \mathrm{~m}\right.$ and $D_{k} / Q_{k}$ are integers), when $n=1,(4,1445,69,391)$ is the local maximum point of the function, and its local maximum value is shown as 69,391 . All points around it have lower values, although the top of the surface looks like a plane.

\section{Conflict of interest statement}

Authors have no conflict of interest to declare.

\section{References}

[1] Abdelsalam HM, Elassal MM. Joint economic lot sizing problem for a three-layer supply chain with stochastic demand. Int J Prod Econ 2014;155:272-83.

[2] Banerjee A. A joint economic-lot-size model for purchaser and vendor. Decis Sci J 1986;17(3):292-311.

[3] Ben-Daya M, As'Ad R, Seliaman M. An integrated production inventory model with raw material replenishment considerations in a three layer supply chain. Int J Prod Econ 2013;143(1):53-61.

[4] Christoph HG, Kim T. Shipment consolidation in a multivendor-single-buyer integrated inventory model. Comput Ind Eng 2014;70:31-42.

[5] Eugene S. MAM2006: Markov anniversary meeting. Raleigh, North Carolina: Boson Books; 2006. p. 1-20.

[6] Chandra C, Grabis J. Inventory management with variable lead-time dependent procurement cost. Omega 2008;36(5): 877-87.
[7] Goyal SK. A joint economic lot size model for purchaser and vendor: a comment. Decis Sci J 1988;19:236-41.

[8] Hans S, Ibrahim RN, Lochert BP. A single-vendor multiplebuyer inventory model with a multiple-shipment policy. Int J Adv Manuf Technol 2006;27(9):1030-7.

[9] Harris FW. How many parts to make at once. Oper Res 1990; 38(6):947-50.

[10] Hoque MA. A vendor-buyer integrated production-inventory model with normal distribution of lead time. Int J Prod Econ 2013;144:409-17.

[11] Jha JK, Kripa S. Single-vendor multi-buyer integrated production-inventory model with controllable lead time and service level constraints. Appl Math Modell 2013;37:1753-67.

[12] Kim T, Glock $\mathrm{CH}$. A multi-stage joint economic lot size model with lead time penalty costs. Comput Ind Eng 2013;66: 133-46.

[13] Kocer UU. Forecasting intermittent demand by Markov chain model. Int J Innovat Comput Info Control 2013;9(8).

[14] Lambert, Douglas M. Supply chain management: processes, partnerships, performance. 3rd ed. 2008.

[15] Leuveano RAC, Jafar FAB, Saleh C, Muhamad MRB, Rahman MNA. Incorporating transportation cost into joint economic lot size for single vendor-buyer. J Softw 2014; 9(5).

[16] Lin JP, Yang MF, Ke MJ. Integrated cooperative inventory models with Preventive Maintenance one-vendor multiplebuyers in the supply chain. J Indus Business Manag 2016; 9(1):22-31.

[17] Lu M, Huang S, Shen ZJM. Product substitution and dual sourcing under random supply failures. Transp Res Part B Methodol 2011;45(8):1251-65.

[18] Lu. A one-vendor multi-buyer integrated inventory model. Eur J Oper Res 1995;81:312-23.

[19] Markov AA. Extension of the law of large numbers to dependent quantities. Izvestiia Fiz.-Matem. Obsch. Kazan Univ. 1906;15(2nd Ser.):135-56.

[20] Ouyang LY, Wu KS. Mixture inventory model involving variable lead time with a service level constraint. Comput Operat Res 1997;24:875-82.

[21] Poonam M, Shaikh A. Optimal ordering policy for an integrated inventory model with stock dependent demand and order linked trade credits for twin ware house system. Uncertain Suppl Chain Manag 2017;5:169-86.

[22] Sarakhsi MK, Ghomi SMTF, Karimi B. A new hybrid algorithm of scatter search and Nelder-Mead algorithm to optimize joint economic lot sizing problem. J Comput Appl Math 2016;292:387-401.

[23] Shah NH, Chaudhari U. Optimal policies for three players with fixed life time and two-level trade credit for time and credit dependent demand. Adv Ind Eng Manag 2015;4(1): 89-100.

[24] Tersine RJ. Principles of inventory and materials management. $3^{\text {rd }}$ ed. Amsterdam, The Netherlands: North Holland; 1988.

[25] Yang MF, Kuo JY, Chen WH, Lin Y. Integrated supply chain cooperative inventory model with payment period being dependent on purchasing price under defective rate condition. Math Probl Eng 2015:1-20. Article ID 513435.

[26] Yang MF, Tseng WC. Three-echelon inventory model with permissible delay in payments under controllable lead time and backorder consideration. Math Probl Eng 2014:1-16. Article ID 809149. 